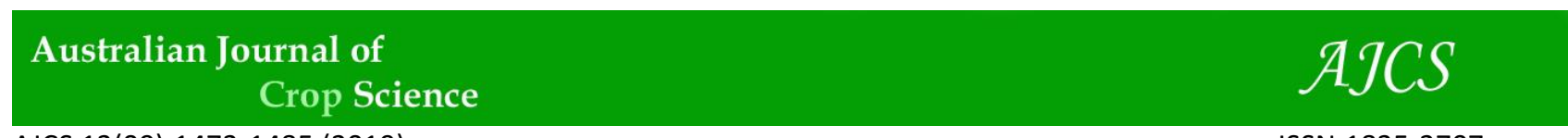

AJCS 13(09):1473-1485 (2019)

ISSN:1835-2707

doi: 10.21475/ajcs.19.13.09.p1561

\title{
Development of a core collection for Sri Lankan cinnamon germplasm based on morphological characterization using an eco-geographic survey
}

\author{
Rumana $\mathrm{Azad}^{1}$, L. Jayasekara ${ }^{2}$, R.A.A.K. Ranawaka ${ }^{3}$, Gamini Senanayake ${ }^{4}$, K.L. Wasantha Kumara ${ }^{4}$, \\ D.K.N.G. Pushpakumara ${ }^{5}$ and Sudarshanee Geekiyanage ${ }^{4^{*}}$
}

\author{
${ }^{1}$ Board of Study in Agriculture, Faculty of Graduate Studies, University of Ruhuna, Matara, Sri Lanka \\ ${ }^{2}$ Department of Mathematics, Faculty of Science, University of Ruhuna, Matara, Sri Lanka \\ ${ }^{3}$ Mid Country Research Station, Department of Export Agriculture, Sri Lanka \\ ${ }^{4}$ Department of Agricultural Biology, Faculty of Agriculture, University of Ruhuna, Mapalana, Kamburupitiya, Sri \\ Lanka \\ ${ }^{5}$ Department of Crop Science, Faculty of Agriculture, University of Peradeniya, Peradeniya, Sri Lanka
}

*Corresponding author: sudarshanee@agbio.ruh.ac.Ik (Dr. Sudarshanee Geekiyanage)

\begin{abstract}
Cinnamomum verum is the most important spice produced by Sri Lanka. This study was carried out to fill the gap of knowledge on diversity of Sri Lankan cinnamon through morphological characterization. Therefore, an eco-geographic survey in major growing areas followed by the development of a core collection and vegetative propagation of the total collection for ex-situ conservation were carried out. Two hundred and sixty nine cinnamon accessions were collected. The average shoot regeneration frequency of 269 accessions was $47.76 \%$ after one month of vegetative propagation. The collection was established at Faculty of Agriculture, University of Ruhuna for further studies. The collection was characterized for 15 quantitative and qualitative characters of leaf, stem and inflorescence among which, a wide variation was detected for leaf characters mainly. Leaf length positively correlated with Leaf width $(+0.643)$ and Petiole length $(+0.483)$. Principal component analysis $(P C A)$ revealed that there were 3 dimensions of PCA explaining $88.85 \%$ of total variance. In Hierarchical cluster analysis based on above characters, 269 accessions were grouped into five clusters at rescaled distance of 0.1 . A representation of $10 \%$ accessions was randomly selected from each cluster to develop a core collection with 33 accessions. The core collection of 33 accessions was clustered into five groups according to the same method at rescaled distance of 0.075 . The core collection is a representation of the total collection as clusters of the two dendograms could be overlapped. Morphological characterization and core collection development during this study will be useful for germplasm management, conservation and varietal improvement through breeding programmes.
\end{abstract}

Keywords: Cluster analysis; morphological characters; Principal Component Analysis; Sri Lankan cinnamon germplasm

Abbreviations: LL_Leaf length, LW_Leaf width, LLWr_Leaf length-width ratio, PL_Petiole length, BT_Bark thickness, LA_Leaf arrangement, LS_Leaf shape, LAP_Leaf apex, LB_Leaf base, LT_Leaf texture, ULC_Upper surface leaf colour, FC_Flush colour, BC_Bark colour, BS_Bark surface, BF_Bark fragrance, BTS_Bark taste.

\section{Introduction}

Sri Lankan cinnamon (Cinnamomum verum) known as true cinnamon is world famous for its delicate and unique flavour. The colour of cinnamon bark varies from light brown to dark brown and the taste of bark had been described as sweet, sweet pungent, bitter pungent and astringent. Cinnamon leaf and bark are used as spices and condiments. Essential oils extracted from the leaves and bark are used in perfumary, flavouring and pharmaceutical industries (Joy et al., 1998). Different biological activities, such as antidiabetic, anti-inflammatory, astringent and diuretic effects led cinnamon popular in folk medicine (Lee et al., 2010a). In modern medicine, cinnamon is combined with other ingredients to treat diarrhea, internal haemorrhages, impotency, typhoid, halitosis, checking nausea, vomiting and for restoring normal skin colour on the face (Warrier et al., 1994).

Cinnamomum verum is one of the most important species in Sri Lankan economy: the export volume of cinnamon and earning for 2016 was 14,692.8 metric tons and 23177.9 million rupees respectively (Sri Lanka Custom, 2017). The genus Cinnamomum of family Lauraceae consists of about 250 species, mostly found in Asia, some parts in South and Central America, and Australia (Mabberley, 2008). In Sri Lanka several species of cinnamon had been explored from central hills and the virgin forest reserve of Sinharaja (Wijesinghe and Pathirana, 2000). According to an ecogeographical survey by Kumarathilake et al. (2010), there are eight Cinnamomum species available in Sri Lanka: indigenous Cinnamomum verum is the cultivated species while other 
species are of wild and endemic cinnamon composing the secondary gene pool, which is at the risk of extinction. Cinnamon grows about 8-15 $\mathrm{m}$ in height in the wild, while height of the cultivated cinnamon is maintained usually at 2$4 \mathrm{~m}$. Cinnamon is mostly cultivated along the coastal belts of Kalutara, Galle and Hambantota districts at an elevation of about $250 \mathrm{~m}$ above mean sea level. The most suitable temperature for its cultivation is between $25^{\circ} \mathrm{C}-32^{\circ} \mathrm{C}$ (Department of Export Agriculture, Sri Lanka. 2013).

Cinnamon flower exhibits protogynous dichogamy leading to cross pollination (Joseph, 1981). As a result, heterogeneous populations are produced (Azad et al., 2015). Vegetative propagation ensures the uniformity of desirable genetic material for propagation of elite lines (Rema et al., 1997). Leaves are the most variable character in Cinnamomum species. According to Ravindran et al. (2004) leaf shape of cinnamon varies from oval or elliptic to lanceolate-oval or narrowly elliptic, $3 \times 7-8 \times 25 \mathrm{~cm}$ in size, shortly or broadly acuminate in leaf apex and acute or cuneate in leaf base. Wijesinghe and Gunarathna (2001) reported about a correlation between leaf characters and yield in seven genotypes of true cinnamon as trees with large round inwardly curved leaves had produced higher cinnamaldehyde content in bark oil, while high quality leaf oil was obtained from the small round leaves.

A core collection is a representative subset of a large number of populations developed for efficient management of a germplasm collection (Diwan et al., 1995). Grouping is the primary and initial step of core collection developmental concept to categorize accessions of germplasm in to morphologically and genetically similar accessions. Moreover, clustering of accessions is useful for evaluation of germplasm, identification of trait-specific accessions, gene discovery, allele mining, genomic study, marker development and molecular breeding (Qui et al., 2013).

Both environmental and genetic effects contribute to phenotypic variation within and among populations (Andrew et al., 2010). Development of a core collection from Sri Lankan cinnamon germplasm is necessary for the use in genetic studies due to the wide genetic diversity potentially depicted in morphological diversity (Azad et al., 2016a). A few molecular studies had been conducted to evaluate genetic differences on Cinnamomum species (Ho and Hung, 2011; Joy and Maridass, 2008; Kameyama, 2012; Soulange et al., 2007; Lee et al., 2010b; Kojoma et al., 2002; Sandigawad and Patil, 2011; Kuo et al., 2010). A genetic analysis of Cinnamomum species had been reported on sequencing $T r n \mathrm{~L}$ intron region, intergenic spacer between trnT-trnL, trnL-trnF, trnH-psbA and nuclear ITS (Abeysinghe et al., 2009). Cinnamomum genetic diversity had been detected in an initial experiment with a limited number of genotypes using RAPD and SRAP (Abeysinghe et al., 2014). Cluster analysis followed by Principal component analysis had been used to cluster Cinnamomum spp. into groups and to show relationships among species on the basis of morphological characters (Ravindran et al., 1991).

The lack of information on genetic basis for key biochemical pathways of cinnamon is a drawback in establishing the identity of Sri Lankan cinnamon and selection for higher quantity and quality of yield for breeding. The information on characterization of chemical constituents and chemical composition variation across the accessions in the country, which is the centre of origin of cinnamon, is not yet available. Genetic factors responsible for higher yield of essential oil are not known. There is no information on ecological adaptability and effect of agro ecological location on chemical yield. Further, no research had been carried out to determine the flavonoid composition and variation across the country, which could be of high importance for production of therapeutic products. There are no accessions yet that can withstand major cinnamon diseases of rough bark disease and leaf spot disease successfully. Molecular markers had not been developed for those diseases yet. Characterization of whole cinnamon germplasm in Sri Lanka would be useful for mining genetic factors for breeding cinnamon.

Therefore, the present study was conducted to characterize Cinnamomum verum germplasm from different locations of major cinnamon growing areas in Sri Lanka in order to develop a core collection for above breeding purposes in the future experiments.

\section{Results}

\section{Variation of morphological characters}

A comprehensive study was conducted on morphological characters of cinnamon during the eco-geographic survey of the 269 accessions. There was a variation in both quantitative and qualitative characters (Fig 2 and Fig 3 and Table 1).

In accordance with previous report by Ravindran et al. (2004), leaves showed a higher variation in the collection:

Leaf length (LL), Leaf width (LW), Leaf length-width ratio (LLWr), Petiole length(PL) varied from 7.43 to $20.26 \mathrm{~cm}, 3.4$ to $10.08 \mathrm{~cm}, 1.58$ to 3.19 and 0.9 to $2.7 \mathrm{~cm}$ respectively. The shape of the lamina (LS) was elliptic to ovate, oval, lanceolate to ovate-lanceolate (Table 1, Fig 2). The apex of the leaf (LAP) was acute, acuminate to long acuminate and acuminate with broad acumen and the base of the leaf (LB) was acute or cuneate or obtuse. The leaves were 3-veined, or 5 -veined with very slender additional basal veins. The upper surface of mature leaf was dark green mostly, while the lower surface was pale green with paler veins. The leaf petiole (PL) was 9-27 $\mathrm{mm}$ and was slightly curved upward.

Axillary and terminal panicles were observed, which formed both from axil and apex of branchlets. Peduncles were highly branched and consisted of long sub-branches (Fig 3). Flowers were pale yellowish green and 8-12 mm long. The number of tepals was 6 in 2 whorls and the shape of the tepal was oblong-lanceolate or ovate.

The fruit of cinnamon ranged from $1.5-2 \mathrm{~cm}$ in length and dark purple in colour. The fruit was a fleshy berry, one seeded, ellipsoid or ovoid in shape and with an enlarged calyx.

\section{Correlation analysis of quantitative characters}

The correlation coefficient was observed among five different quantitative characters of two hundred sixty nine accessions (Table 2). LL positively correlated with LW (+0.643), LLWr +0.417 and PL $(+0.483)$ while, LW was positively correlated with $\mathrm{PL}(+0.395)$ and negatively correlated with LLWr (-0.414). The significant correlation 
Table 1. Frequency of qualitative characters in cinnamon collection of 269 accessions.

\begin{tabular}{|c|c|c|}
\hline Qualitative character & Pattern/ Color type & Frequency of accessions \\
\hline \multirow[t]{4}{*}{ Leaf arrangement (LA) } & Opposite & 16 \\
\hline & Sub-opposite & 97 \\
\hline & Opposite or sub-opposite & 31 \\
\hline & Opposite to sub-opposite & 125 \\
\hline \multirow[t]{9}{*}{ Leaf shape (LS) } & Elliptic & 112 \\
\hline & Broadly elliptic & 31 \\
\hline & Narrowly elliptic & 45 \\
\hline & Ovate & 42 \\
\hline & Broadly ovate & 4 \\
\hline & Oval & 2 \\
\hline & Lanceolate & 29 \\
\hline & Ovate-lanceolate & 2 \\
\hline & Oblong-lanceolate & 2 \\
\hline \multirow[t]{8}{*}{ Leaf apex (LAP) } & Acute & 85 \\
\hline & Obtuse & 4 \\
\hline & Acuminate & 92 \\
\hline & Subacuminate & 18 \\
\hline & Gradually acuminate & 19 \\
\hline & Long acuminate & 19 \\
\hline & Narrowly acuminate & 19 \\
\hline & Acuminate with broad acumen & 13 \\
\hline \multirow[t]{6}{*}{ Leaf base(LB) } & Acute & 147 \\
\hline & Subacute & 79 \\
\hline & Cuneate & 17 \\
\hline & Rounded & 11 \\
\hline & Obtuse & 2 \\
\hline & $\begin{array}{l}\text { Obtuse, contracted into petiole, then shortly } \\
\text { cuneate }\end{array}$ & 13 \\
\hline \multirow[t]{6}{*}{ Leaf texture (LT) } & Coriacerous & 81 \\
\hline & Subcoriaceous & 4 \\
\hline & Rigidly coriaceous & 4 \\
\hline & Thinly to stiffly coriaceous & 2 \\
\hline & Chartaceous to rigidly chartaceous & 40 \\
\hline & Chartaceous & 138 \\
\hline \multirow[t]{2}{*}{ Upper surface leaf coluor (ULC) } & Dark green & 234 \\
\hline & Green & 35 \\
\hline \multirow[t]{12}{*}{ Flush colour (FC) } & $2.5 R 4 / 10$ & 1 \\
\hline & $2.5 R 7 / 6$ & 16 \\
\hline & $5 R P 6 / 10$ & 4 \\
\hline & $2.5 \mathrm{R} 6 / 8$ & 45 \\
\hline & $5 G Y 7 / 10$ & 39 \\
\hline & $2.5 \mathrm{GY} 8 / 10$ & 32 \\
\hline & $2.5 \mathrm{GY} 8 / 6$ & 3 \\
\hline & $2.5 \mathrm{R} 4 / 8$ & 35 \\
\hline & $5 R$ 4/10 & 3 \\
\hline & $2.5 R 7 / 8$ & 55 \\
\hline & $5 R P 4 / 12$ & 25 \\
\hline & $5 R P 6 / 8$ & 11 \\
\hline \multirow[t]{5}{*}{ Bark colour (BC) } & Brown & 160 \\
\hline & Whitish brown & 32 \\
\hline & Light brown & 24 \\
\hline & Greenish to brown & 35 \\
\hline & Brownish to black & 18 \\
\hline \multirow[t]{4}{*}{ Bark surface (BS) } & Slightly rough & 86 \\
\hline & Rough & 88 \\
\hline & Very rough & 55 \\
\hline & Smooth & 40 \\
\hline \multirow[t]{4}{*}{ Bark fragrance (BF) } & Weak fragrant aroma & 18 \\
\hline & Intermediate fragrant aroma & 78 \\
\hline & Good fragrant aroma & 41 \\
\hline & Strong fragrant aroma & 132 \\
\hline
\end{tabular}




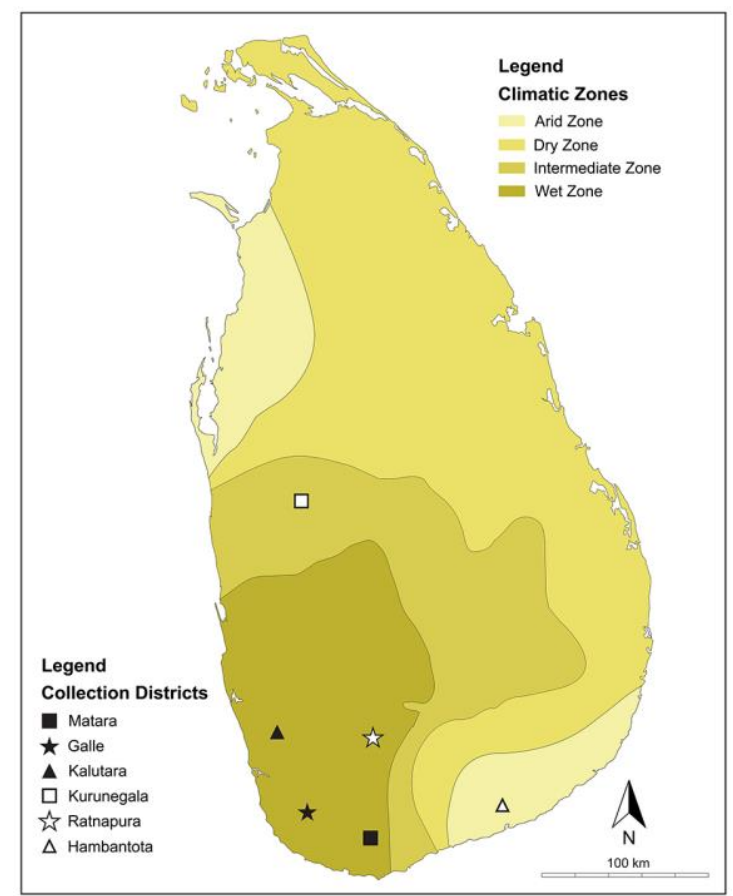

Fig 1. Map of Sri Lanka showing different climatic zones and collection sites of cinnamon germplasm from six major cinnamon growing districts.

Table 2. The correlations between selected quantitative characters according to Pearson's Correlation coefficient in total collection of 269 accessions.

\begin{tabular}{llllll}
\hline Variable & LL & LW & LLWr & PL & BT \\
\hline LL & - & $0.643^{* *}$ & $0.417^{* *}$ & $0.483^{* *}$ & 0.027 \\
LW & & - & $-0.414^{* *}$ & $0.395^{* *}$ & 0.002 \\
LLWr & & - & 0.107 & 0.030 \\
PL & & & - & 0.076 \\
BT & & & & -
\end{tabular}

** Correlation is significant at the 0.01 level. LL: leaf length, LW: leaf width, LLWr: Leaf length and width ratio, PL: petiole length, BT: Bark thickness.

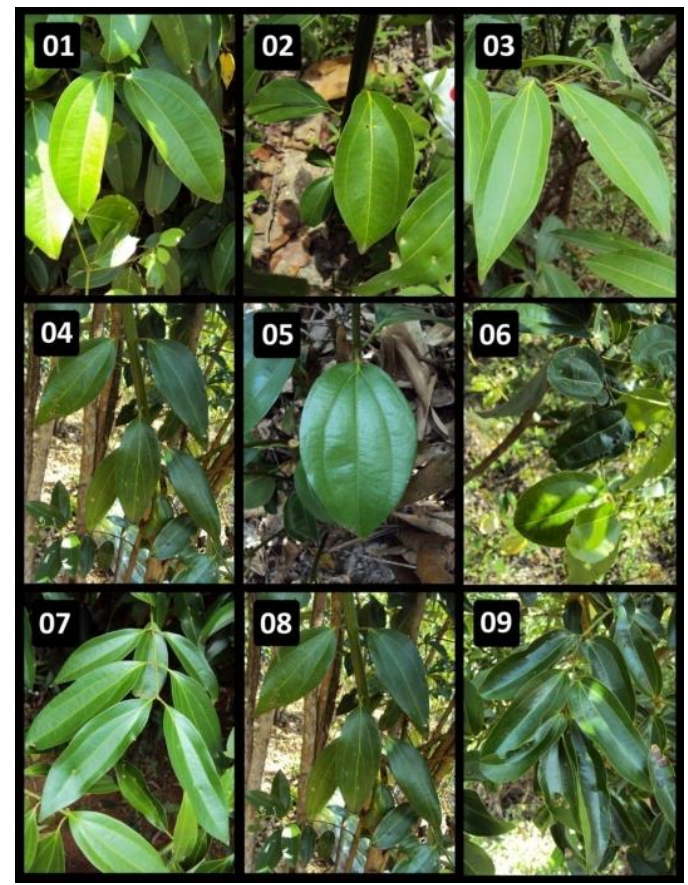

Fig 2. Variation of leaf shape among 269 accessions; 01 Elliptic, 02 Broadly elliptic, 03 Narrowly elliptic, 04 Ovate, 05 Broadly ovate, 06 Oval, 07 Lanceolate, 08 Ovate-lanceolate, 09 Oblong-lanceolate. 
Table 3. Mean (M), Standard Deviation (SD) and Coefficient of Variation (CV\%) of quantitative characters of cinnamon accessions belonging to five clusters.

\begin{tabular}{|c|c|c|c|c|c|c|c|c|c|c|c|c|c|c|c|}
\hline \multirow{2}{*}{$\begin{array}{l}\text { Cluster } \\
\text { number }\end{array}$} & \multicolumn{3}{|l|}{ LL } & \multicolumn{3}{|l|}{ LW } & \multicolumn{3}{|l|}{ LLwr } & \multicolumn{3}{|l|}{$\mathrm{PL}$} & \multicolumn{3}{|l|}{ BT } \\
\hline & $M$ & SD & CV\% & $M$ & SD & CV\% & $M$ & SD & CV\% & $M$ & SD & CV\% & $M$ & SD & CV\% \\
\hline 1 & 10.69 & 1.08 & 10.14 & 4.67 & 0.38 & 8.08 & 2.30 & 0.27 & 11.57 & 1.40 & 0.25 & 18.58 & 1.67 & 0.48 & 28.68 \\
\hline 2 & 12.68 & 1.10 & 8.64 & 5.45 & 0.32 & 5.89 & 2.34 & 0.28 & 12.12 & 1.56 & 0.32 & 20.82 & 1.72 & 0.41 & 23.95 \\
\hline 3 & 13.53 & 0.85 & 6.26 & 6.68 & 0.58 & 8.63 & 2.04 & 0.17 & 8.52 & 1.72 & 0.31 & 17.99 & 1.66 & 0.38 & 22.93 \\
\hline 4 & 16.18 & 1.22 & 7.51 & 6.32 & 0.54 & 8.54 & 2.58 & 0.26 & 10.23 & 1.83 & 0.33 & 18.07 & 1.71 & 0.48 & 27.88 \\
\hline 5 & 18.08 & 1.53 & 8.47 & 8.50 & 0.76 & 8.89 & 2.15 & 0.33 & 15.31 & 2.00 & 0.43 & 21.63 & 1.77 & 0.52 & 29.31 \\
\hline
\end{tabular}

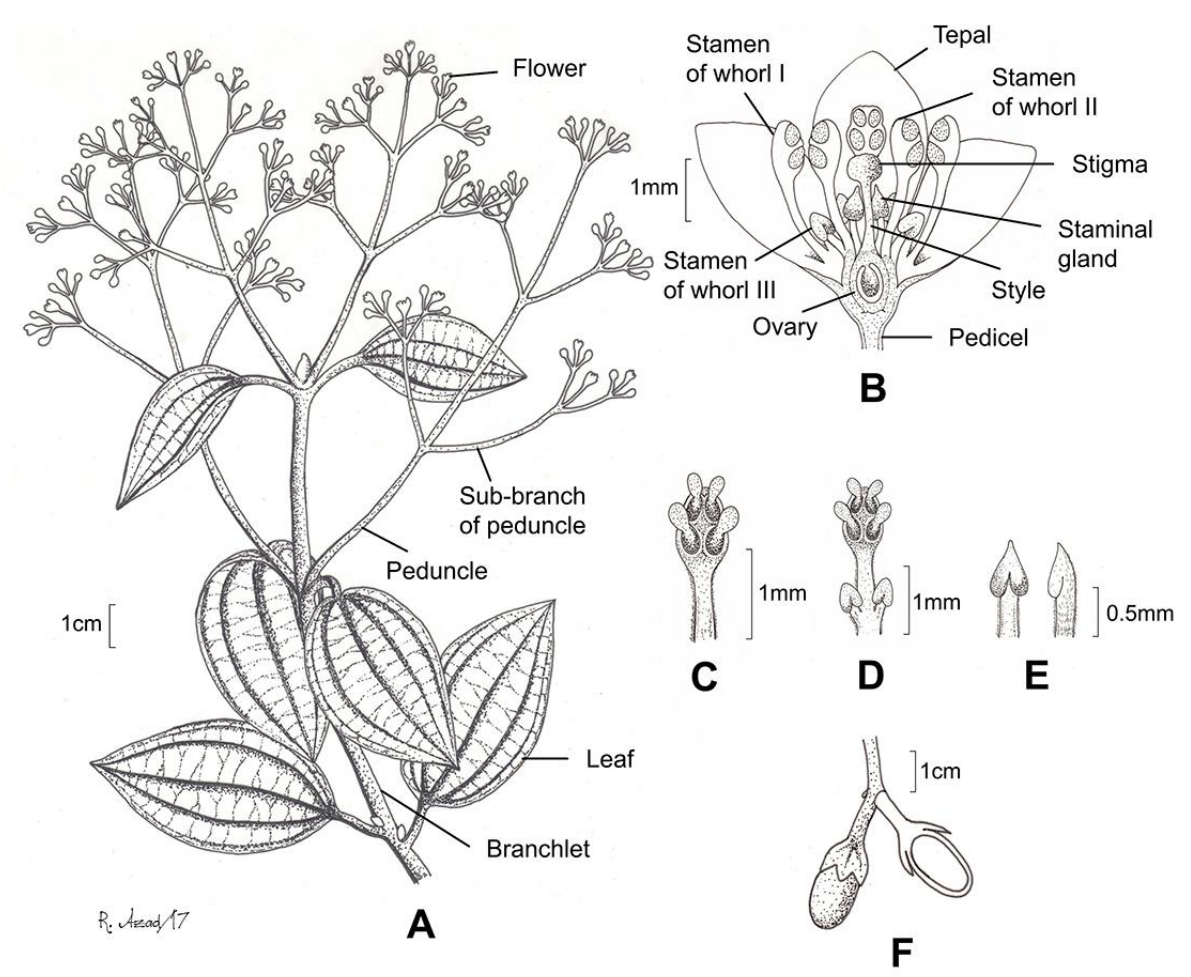

Fig 3. Cinnamomum verum Presl. A. Flowering shoot, B. Longitudinal section of flower, C. Stamen of whorl I, D. Stamen of whorl II with stamen of whorl III at the base, E. Staminal gland, F. Longitudinal section of mature fruit (Illustrations were made by the first author).

Table 4. Principal Component Analysis of total collection of 269 accessions and core collection of 33 accessions

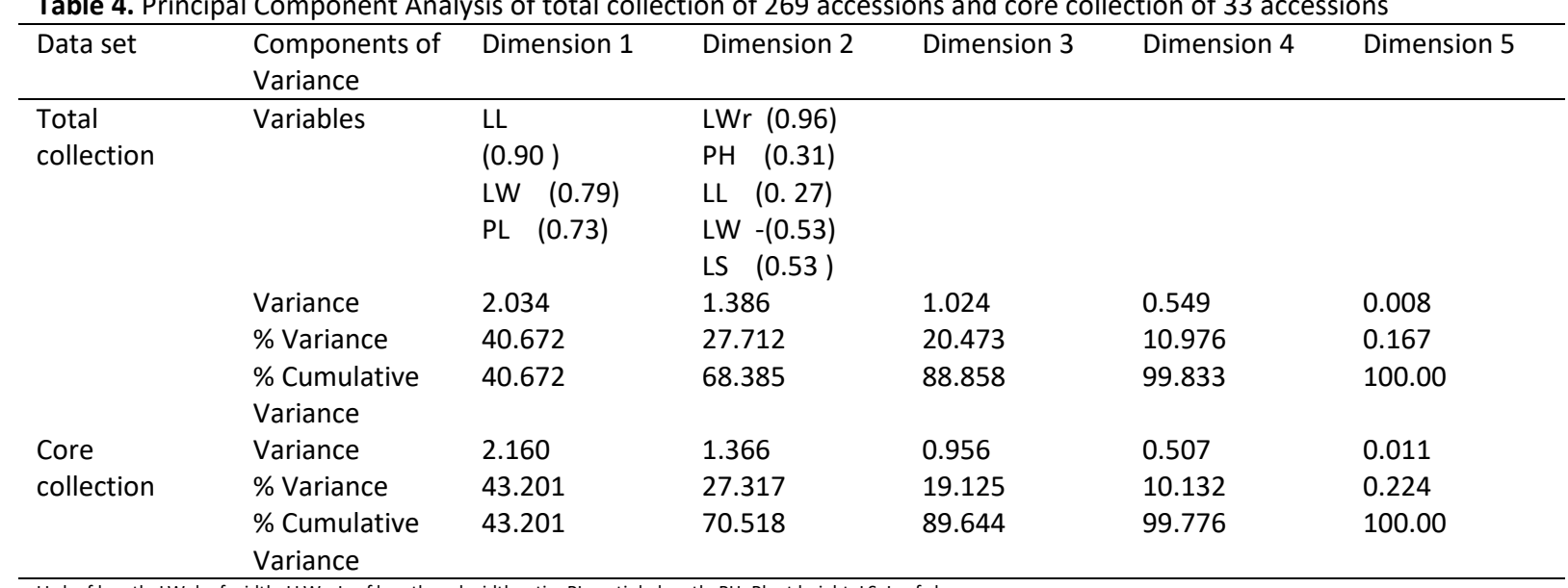




\section{Linkage Distance}

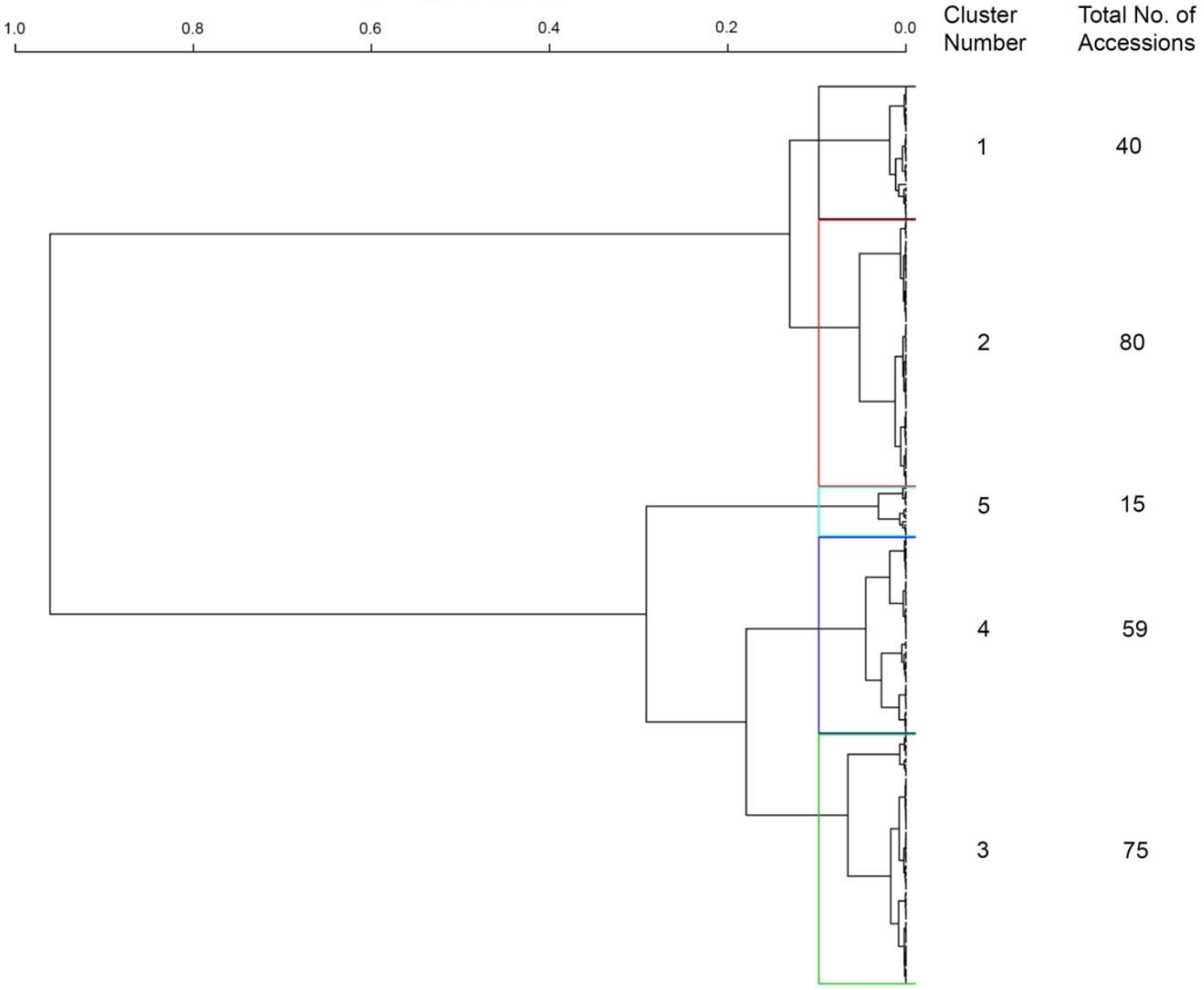

Fig 4. Cluster analysis of 269 cinnamon accessions based on fifteen morphological characters.

Table 5. Percentage of shoot formation from each collection after one month of vegetative propagation.

\begin{tabular}{lc}
\hline Collection No. & Percentage of shoot formation \\
\hline 1 & 45.65 \\
2 & 50.94 \\
3 & 56.0 \\
4 & 55.56 \\
5 & 56.0 \\
6 & 40.0 \\
7 & 24.0 \\
8 & 31.25 \\
9 & 60.0 \\
10 & 52.38 \\
11 & 42.30 \\
12 & 66.66 \\
13 & 30.77 \\
14 & 59.62 \\
15 & 63.89 \\
16 & 25.0 \\
17 & \\
\hline
\end{tabular}



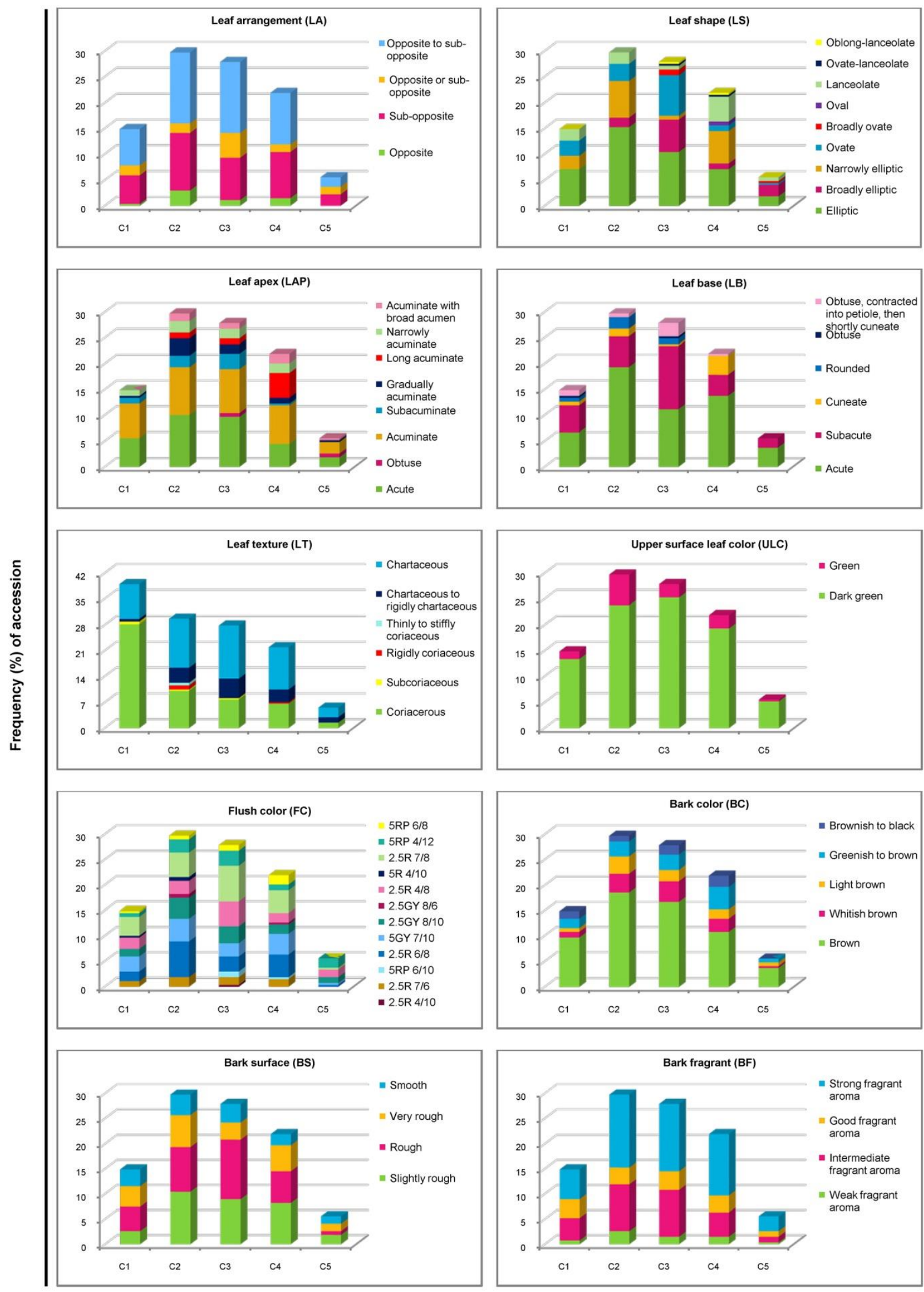

Cluster

Fig 5. Variation of qualitative characters among clusters resulted through Cluster analysis of 269 accessions. 


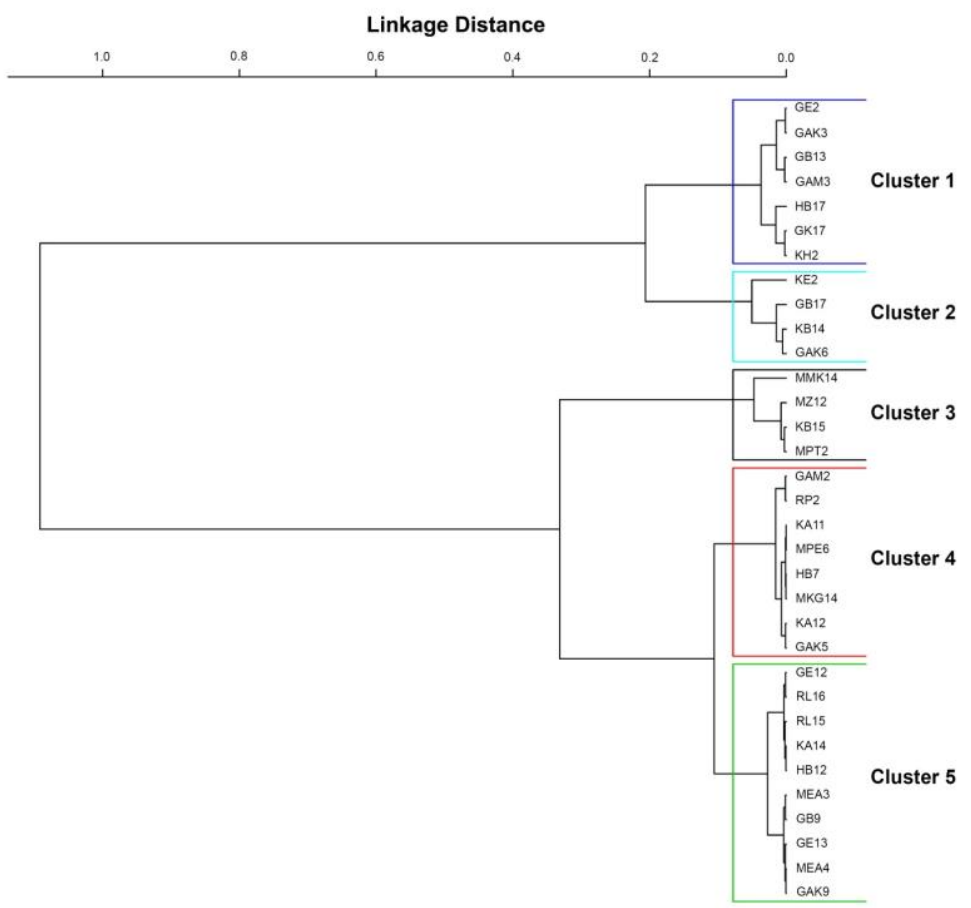

Fig 6. Dendogram of the core collection of 33 cinnamon accessions based on fifteen morphological characters.

Bark taste (BTS)
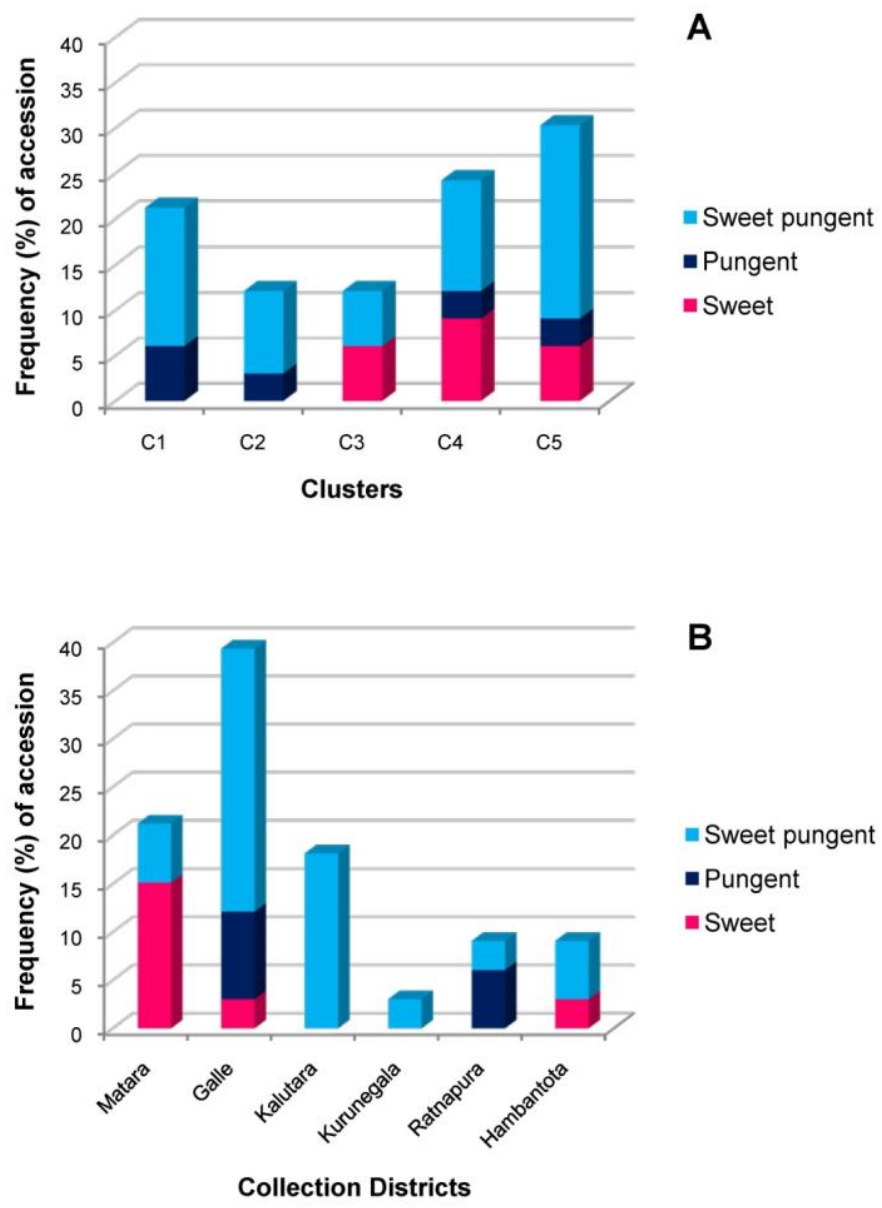

Fig 7. Variation of bark taste in the clusters of core collection (A) and collection Districts (B). 


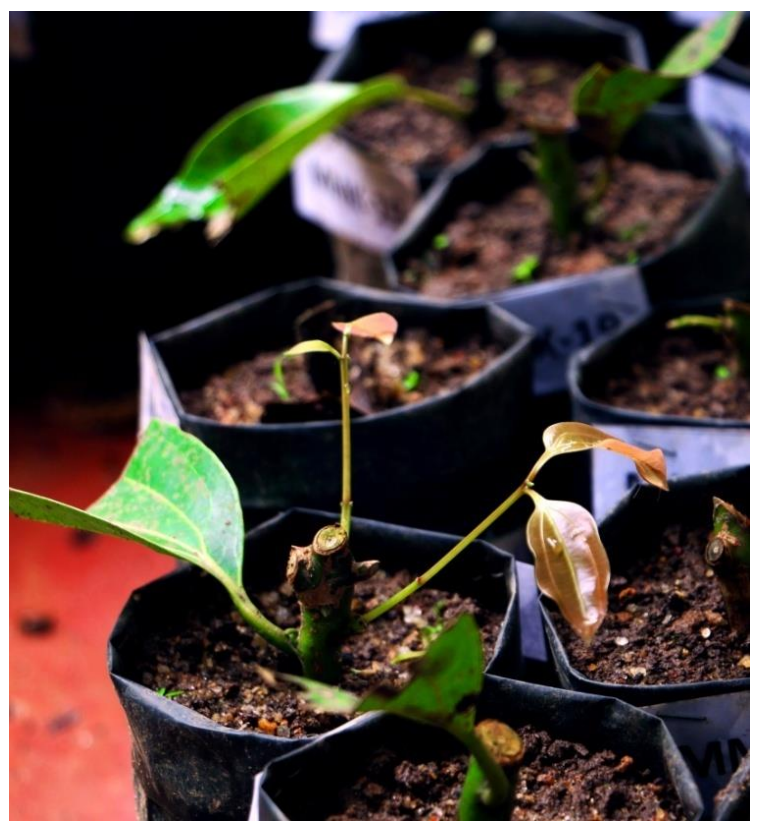

Fig 8. Shoot formation in a cinnamon cutting through vegetative propagation.

among the characters will provide plant breeders an understanding on manipulation of such characters.

\section{Principal Component Analysis (PCA)}

The Principal component analysis (PCA) was carried out using 15 quantitative and qualitative morphological characters of 269 accessions, which revealed that there were 3 dimensions of PCA (with an Eigen value above 1) explaining $88.85 \%$ of total variance.

Quantitative characters of LL, LW and PL significantly contributed to dimension 1 of PCA for $40.67 \%$ variance, while qualitative characters of LS and LLWr were included in dimension 2 contributing to the $27.71 \%$ of variance. Quantitative character of Plant height (PH) was included in dimension 3 with $20.47 \%$ of total variance (Table 4 ).

\section{Cluster analysis and descriptive statistics of quantitative characters of clustered accessions}

The cluster analysis using Ward's method through Facto Mine R (Lê et al., 2008) classified the 269 cinnamon accessions in to five clusters at a rescaled distance of 0.1 (Fig 4). Accessions were dispersed among clusters irrespective of their eco-geographic location. Average LL, LW and PL varied from $10.69 \pm 1.08 \mathrm{~cm}$ to $18.08 \pm 1.53 \mathrm{~cm}, 4.67 \pm 0.38 \mathrm{~cm}$ to $8.5 \pm 0.76 \mathrm{~cm}$ and $1.4 \pm 0.25 \mathrm{~cm}$ to $2 \pm 0.43 \mathrm{~cm}$ from cluster 1 to cluster 5. Bark thickness (BT) varied from $1.66 \pm 0.38 \mathrm{~mm}$ to $1.77 \pm 0.52 \mathrm{~mm}$ from cluster 3 to 5 (Table 3 and Fig 4).

The coefficient of variation (CV\%) of quantitative characters was calculated to determine the variation of characters in each cluster. Accessions from cluster no. 5 gave higher CV\% for PL (21.63\%) and BT (29.31\%). A higher CV\% for PL (20.82\%) was detected in cluster no. 2 and accessions from cluster no. 1 had higher CV\% of LL (10.14\%) and BT (28.68\%) indicating their higher variability.
The dispersion of qualitative characters among clusters was evident as well (Fig 5). The highest frequency of accessions with opposite (2.97\% accessions) and sub-opposite (11.15\% accessions) LAs were found in cluster no. 2. The elliptic LS was observed as the most common LS where $15.24 \%$ accessions with elliptic LS were placed in cluster no. 2 . The highest number of accessions with broadly elliptic (6.32\% accessions) and ovate (7.81\% accessions) LS was found in cluster no. 3. The acute and acuminate LAP were detected as most common in all the five clusters, where cluster no. 4 has a large number of accessions with long acuminate $(4.83 \%$ accessions) LAP. The highest frequency of accessions with acute (19.33\% accessions) and subacute ( $12.27 \%$ accessions) LB was placed in cluster no. 2 and cluster no. 3 respectively. The large number of accessions reported to be coriacerous (28.21\% accessions) leaf texture, and placed in cluster no. 1. The leaf FC was a highly variable qualitative character, where highest frequency of accessions with 2.5R 6/8 (7.06\% accessions) and $2.5 \mathrm{GY} \quad 8 / 10 \quad(4.09 \%$ accessions $)$ were recorded in cluster no. 2 , and $2.5 \mathrm{R} 4 / 8$ (4.83\% accessions) and $2.5 R 7 / 8$ (7.06\% accessions) were recorded in cluster no. 3. Brown bark colour $(\mathrm{BC})$ and slightly rough and rough bark surface (BS) were common among accessions and such accessions were distributed over all clusters. Only $11.80 \%$ accessions had rough BS in cluster no. 3. The strong bark fragrance $(\mathrm{BF})$ with $14.50 \%, 13.38 \%$ and $12.27 \%$ accessions were from cluster no. 2,3 , and 4 respectively. The equal percentages of accessions $(9.29 \%$ accessions) with intermediate fragrance were placed in cluster no. 2 and 3.

\section{Development of a core collection and evaluation of Bark taste (BTS) for core collection}

A core collection with 33 accessions was developed taking $10 \%$ of the accessions from each cluster of 269 accessions (Fig 6). In PCA, dimension 1,2 and 3 of PCA (with an Eigen value above 1 ) contributed for $43.20 \%, 27.31 \%$ and $19.12 \%$ 
of variance respectively making a cumulative value of $89.64 \%$ of total variance (Table 4 ).

The 33 cinnamon accessions were grouped into five clusters at rescaled distance of 0.075 . As BTS of cinnamon is an important variable, it was evaluated according to clusters and collection locations (Fig 7). The highest frequency of accessions with Sweet pungent taste (21.21\% accessions), Pungent taste $(6.06 \%$ accessions) and Sweet taste $(9.09 \%$ accessions) were recorded in cluster no. 5, 1 and 4 respectively (Fig 7A). The highest and the second highest numbers of accessions with Sweet pungent taste were recorded from Galle (27.27\% accessions) and Kalutara (18.18\% accessions). The highest numbers of accessions with Sweet taste $(15.15 \%)$ and pungent taste $(9.09 \%)$ were recorded from Matara and Galle Districts respectively (Fig 7B).

\section{Vegetative propagation and establishment of ex-situ collection in the field}

The average shoot regeneration frequency of 269 accessions was $47.76 \%$ after one month of vegetative propagation (Table 5 and Fig 8). However, the accessions survived until field planting were eighty, which were established in the cinnamon garden at Faculty of Agriculture, University of Ruhuna for further studies.

\section{Discussion}

Five quantitative morphological characters of LL, LW, LLWr, $P L$ and $B T$ and 10 qualitative morphological characters of $L A$, $L S$, LAP, LB, LT, ULC, FC, BC, BS, and BF were variable among 269 accessions. The environment and growth stage independent quantitative and qualitative characters would indicate the genetic diversity among accessions (Azad et al., 2016a).

In this study, significant correlations were detected among LL, LW, LLWr and PL. PCA is commonly used to analyze large data sets. It has been used to evaluate germplasm of rice (Sohrabi et al., 2012), vineyard peach (Nikolic et al., 2010), peach (Perez et al., 1993), loquat (Leguizamón et al., 2003; Martinez-Calvo et al., 2008), and apricot (Yilmaz et al., 2012; Ruiz and Egea, 2008). Its main purpose is to extract the important information from the table, to represent it as a set of new orthogonal variables called principal components, and to show the pattern of similarity of the observations (Abdi and Williams, 2010).

Cluster analysis grouped all the 269 cinnamon accessions in to five clusters. Ten percent of total collection was selected to make the core collection (Rao and Hodgkin, 2002). There are previous reports on core collection developments: cluster analysis is an essential technique for data mining process, which is used for identification and clustering the relevant groups of genes and samples (Jiang et al., 2004). The mini core collection can be a representative for a large population with minimum redundancies and minimum losses of original diversity (Studnicki et al., 2013). Development of mini core collection can be exploited in plant breeding and germplasm conservation (Ren et al., 2012; Santra et al., 2013; Zhang et al., 2012). A mini core collection from a large diversity set of Sri Lankan traditional rice accessions was developed by Rathnathunga et al.
(2016), which was later utilized for analysis of response to photoperiod ( Rathnathunga and Geekiyanage 2017).

As Sri Lankan cinnamon germplasm from diverse agroecological regions exhibits a wide variation in morphological characters, there is a need for a development of a representative diversity research set for its utilization in breeding programmes. Therefore, $10 \%$ of 269 accessions were represented as a core collection. A total of 33 accessions were selected from the total 269 accessions.

Assessment of Bark taste (BTS) of core collection with 33 cinnamon accessions considering collection locations showed that accessions with Sweet pungent taste was highest in Galle (27.27\% accessions), following $18.18 \%$ accessions in Kalutara. While highest frequency of accessions with Sweet (15.15\% accessions) and Pungent (9.09\% accessions) taste were observed in Matara and Galle Districts respectively. As mentioned by Thomas and Kuruvilla (2012), the geographical origin and conditions of processing of spice has a great influence on chemical composition of a spice which affect its odor and taste. Moreover, cinnamaldehyde is the main constituent which is responsible for sweet taste.

In this study, the wide morphological variation of Sri Lankan cinnamon germplasm from main growing areas were characterized during the survey for the first time in Sri Lanka according to the best of our knowledge. Such wide morphological variations would indicate the potential genetic diversity in the centre of origin of cinnamon.

\section{Materials and methods}

\section{Eco-geographical survey of cinnamon accessions in Sri Lanka}

More than 30 years old 47 cinnamon cultivated lands from major cinnamon growing areas of Matara, Galle, Kalutara, Kurunegala, Ratnapura and Hambantota districts were selected with the help of Department of Export Agriculture during June, 2014 to April, 2015 (Fig 1). A total of 269 accessions were collected on the basis of apparently morphological differences. Accessions were named with a code to represent the district and accession number and morphologically characterized on sites and at laboratory. Braches from each selected accession were inserted into polythene bags with water to dip the cut end. Airconditioning of $26^{\circ} \mathrm{C}$ was maintained during transport.

\section{Evaluation of morphological traits}

Five quantitative morphological characters of Leaf length (LL), Leaf width (LW), Leaf length-width ratio (LLWr), Petiole length (PL) and Bark thickness (BT) were measured from 269 accessions and for each character average value of five readings were taken for analysis. Ten qualitative morphological characters of Leaf arrangement (LA), Leaf shape (LS), Leaf apex (LAP), Leaf base (LB), Leaf texture (LT), Upper surface leaf colour (ULC), Flush color (FC), Bark colour $(B C)$, Bark surface $(B S)$, and Bark fragrance $(B F)$ were recorded from 269 accessions on site. FC had been observed following Munsell colour chart for plants (Munsell Colour, 1977). All qualitative measurements were done following the Descriptors for Cinnamon (Cinnamomum verum) 
published by the Team of TURIS 2013 Project (Azad et al., 2016b).

Additionally, the morphologies of inflorescence, flower and fruit were observed from selected accessions considering the availability during collection. Leaf venation was also recorded from selected accessions.

\section{Vegetative propagation and establishment of an ex-situ collection}

Vegetative propagation and field planting were carried out according to the recommendation by Department of Export Agriculture: Polythene bags of $20 \mathrm{~cm} \times 12.5 \mathrm{~cm}$ were prepared with equal amounts of top soil, cow dung, sand and coir dust. Five stem cuttings of semi-hard wood of $2.5-$ $4.0 \mathrm{~cm}$ diameter with 1 to 2 leaves and active buds from each accession were taken for vegetative propagation. Pots were placed under a propagator in a shady place of natural vegetation at Faculty of Agriculture, University of Ruhuna. Number of cuttings producing shoots was recorded and regeneration frequency was calculated after one month of planting. After one month, plants regenerated by vegetative propagation were transferred to a shade house. When the propagated plants reached to the height of $30 \mathrm{~cm}$, they were transferred to the main field for the growth, development and conservation. Spacing for field planting was $1 \mathrm{~m} \times 1 \mathrm{~m}$ and $1 \mathrm{~m} \times 1 \mathrm{~m}$ between rows and within rows respectively. The pit size was $30 \mathrm{~cm} \times 30 \mathrm{~cm} \times 30 \mathrm{~cm}$. Each pit was filled with compost ( $1 \mathrm{~kg}$ per pit) and rock phosphate ( $5 \mathrm{~g}$ per pit). Plants were irrigated daily during first 3 weeks of planting. Each accession was named in the field with the code at collection site.

\section{Statistical analysis}

ANOVA, correlation and Principal component analysis based on quantitative morphological characters

Morphological analysis of collected samples was done considering both quantitative and qualitative characters. Descriptive statistics such as mean, standard deviation, coefficient of variation and correlation coefficient for five quantitative characters were calculated. Principal Component Analysis (PCA) was conducted with 15 quantitative and qualitative characters in order to identify the patterns of morphological variation using Facto Mine R.

\section{Clustering of accessions based on quantitative and qualitative characters}

Clustering of 269 accessions into five groups was carried out with fifteen morphological characters (except for characters of inflorescence, flower and fruit) following Ward's hierarchical algorithm based on squared Euclidean distances using Facto Mine $R$ at a rescaled distance of 0.1 (Lê et al., 2008). Hierarchical clustering could group similar or closely related accessions into clusters.

The core collection of 33 accessions was clustered into five groups according to the same method and five clusters were derived at rescaled distance of 0.075 .

\section{Development of core collection and evaluation of Bark taste (BTS)}

The 269 cinnamon accessions were clustered into five groups. As a large number of data is problematic to handle in genetic diversity analysis, $10 \%$ of the collection can be taken for representation (Rao and Hodgkin, 2002). Therefore, $10 \%$ accessions from each cluster at rescaled distance of 0.01 were taken for core collection development with 33 accessions. Thus, Bark taste (BTS) which is one of important character for cinnamon was evaluated for clusters of the core collection and collection locations.

\section{Conclusion}

The eco-geographic survey of 269 Sri Lankan cinnamon accessions revealed that selected morphological characters were variable among accessions. The cluster analysis classified the 269 cinnamon accessions in to five clusters at a rescaled distance of 0.1 . Average $\mathrm{LL}, \mathrm{LW}$ and PL varied from $10.69 \pm 1.08 \mathrm{~cm}$ to $18.08 \pm 1.53 \mathrm{~cm}, 4.67 \pm 0.38 \mathrm{~cm}$ to $8.5 \pm$ $0.76 \mathrm{~cm}$ and $1.4 \pm 0.25 \mathrm{~cm}$ to $2 \pm 0.43 \mathrm{~cm}$ from cluster 1 to cluster 5 . BT varied from $1.66 \pm 0.38 \mathrm{~mm}$ to $1.77 \pm 0.52 \mathrm{~mm}$ from cluster 3 to 5 . The highest percentage of opposite (2.97\% accessions) and sub-opposite ( $11.15 \%$ accessions) LA were found in cluster no. 2 . The elliptic LS (15.24\%) was the highest percentage from cluster no. 2 . The highest frequency of acute (19.33\% accessions) LB was placed in cluster no. 2. A large number of accessions was reported to have coriacerous ( $28.21 \%$ accessions) LT from cluster no. 1 . The leaf FC was a highly variable qualitative character. The highest frequency of accessions with 2.5R 6/8 (7.06\% accessions) was reported from cluster no. 2 and with $2.5 \mathrm{R}$ $7 / 8$ (7.06\% accessions) from cluster no. 3. A large number of accessions was reported to have brown bark colour and above accessions were dispersed across all clusters. The bark surface of the accessions was mostly slightly rough and rough, which were dispersed among all clusters. Only $11.80 \%$ accessions had rough bark surface in cluster no. 3 . The $14.50 \%, 13.38 \%$ and $12.27 \%$ accessions with strong bark fragrant were reported from cluster no. 2, 3, and 4 respectively. The equal percentages of accessions $(9.29 \%$ accessions) with intermediate fragrant aroma were placed in cluster no. 2 and 3. Evaluation of BTS for core collection showed that accessions with Sweet pungent taste was highest in Galle $(27.27 \%$ accessions) and second highest $(18.18 \%)$ in Kalutara. The highest number of accessions with Sweet and Pungent tastes were from Matara (15.15\% accessions) and Galle districts (9.09\% accessions) respectively. Therefore, it is clearly manifested that all clusters are highly variable in comparison to qualitative characters and all clusters are of good representation of both qualitative and quantitative characters.

The core collection of 33 accessions was a representation of the total 269 cinnamon accessions.

\section{Acknowledgements}

Authors wish to acknowledge the project Transforming University of Ruhuna into International Status (TURIS) 2013 grant (RU/TURIS/PhD/03) for financial support of this study. Authors are extremely thankful to Mr. Gamini Wijesingha and Mrs. Sheron Weerasooriya from National Cinnamon 
Research and Training Center and Extension Officers of Department of Export Agriculture (DEA) for assistance during germplasm collection.

\section{Conflict of interest}

The authors declare that they have no conflict of interest.

\section{References}

Abeysinghe PD, Samarajeewa NGCD, Li G, Wijesinghe KGG (2014) Preliminary investigation for the identification of Sri Lankan Cinnamomum species using randomly amplified polymorphic DNA (RAPD) and sequence related amplified polymorphic (SRAP) markers. J Natn Sci Foundation Sri Lanka. 42(3):175-182.

Abeysinghe PD, Wijesinghe KGG, Tachida H, Yoshda T (2009) Molecular characterization of cinnamon (Cinnamomum verum Presl.) accessions and evaluation of genetic relatedness of cinnamon species in Sri Lanka based on TrnL intron region, intergenic spacer between trnT-trnL, trnLtrnF, trnH-psbA and nuclear ITS. Res J Agr Biol Sci. 5(6):1079-1088.

Abdi H, Williams LJ (2010) Principal component analysis. WIREs Comp Stat. 2(4):433-459.

Andrew RL, Wallis IR, Harwood CE, Foley WJ (2010) Genetic and environmental contributions to variation and population divergence in a broad-spectrum foliar defence of Eucalyptus tricarpa. Ann Bot. 105:707-717.

Azad R, Senanayake G, Kumara KLW, Ranawaka RAAK., Pushpakumara DKNG, Wijesinghe KGG, Geekiyanage S (2015) Morphological variation within progeny and deviations from mother plant reveal the allele richness in Cinnamomum verum germplasm: a case study from Deiyandara, Matara collection at the early vegetative stage. Trop Agri Res Ext. 18(4):163-167.

Azad R, Ranawaka RAAK., Senanayake G, Kumara KLW, Wijesinghe KGG, Pushpakumara DKNG, Geekiyanage S (2016a) Morphological variation of cinnamon (Cinnamomum verum Persl) germplasm in Matara District of Sri Lanka. Int J Minor Fruits Med Aromat Plants. 2(1):614.

Azad R, Senanayake G, Kumara KLW, Pushpakumara DKNG, Geekiyanage S (Team of TURIS 2013 project) (2016b) Descriptors for Cinnamon (Cinnamomum verum). University of Ruhuna, Sri Lanka. ISBN 978-955-1507-49-7. p. 1-68.

Department of Export Agriculture, Sri Lanka (2013) Cinnamon.

http://www.exportagridept.gov.lk/web/index.php?option =com_content\&view=article\&id=128\&ltemid=159\&lang=e n. Accessed 9 April 2018.

Diwan N, Mclntosh MS, Bauchan GR (1995) Methods of developing a core collection of annual Medicago species. Theor Appl Genet. 90(6):755-761.

Jiang D, Tang C, Zhang A (2004) Cluster analysis for gene expression data: A survey. IEEE Trans Knowl Data Eng. 16(11):1370-1386.

Joy P, Maridass M (2008) Inter species relationship of Cinnamomum species using RAPD marker analysis. Ethnobot Leaflets. 12:476-480.
Joy PP, Thomas J, Samuel M (1998) Cinnamon (Cinnamomum verum Presl) for flavour and fragrance. Pafai J. 20(2):37-42.

Joseph J (1981) Floral biology and variation in cinnamon. PLACROSYM - IV, pp. 431-434.

Ho KY, Hung TY (2011) Cladistic relationships within the genus Cinnamomum (Lauraceae) in Taiwan based on analysis of leaf morphology and inter-simple sequence repeat (ISSR) and internal transcribed spacer (ITS) molecular markers. Afr J Biotechnol. 10:4802-4815.

Kameyama Y (2012) Development of microsatellite markers for Cinnamomum camphora (Lauraceae). Am J Bot. 99(1):e1-e3.

Kuo DC, Lin CC, Ho KC, Cheng YP, Hwang SY, Lin TP (2010) Two genetic divergence centers revealed by chloroplastic DNA variation in populations of Cinnamomum kanehirae Hay. Conserv Genet. 11:803-812.

Kojoma M, Kurihara K, Yamada K, Sekita S, Satake M, Lida O (2002) Genetic identification of cinnamon (Cinnamomum spp.) based on the trnL-trnF chloroplast DNA. Planta Med. 68:94-96.

Kumarathilake DMHC, Senanayake SGJN, Wijesekara GAW, Wijesundara DSA, Ranawaka RAAK (2010) Extinction risk assessments at the species level: National red list status of endemic wild cinnamon species in Sri Lanka. Trop Agric Res. 21(3):247-257.

Lee SC, Chiou SJ, Yen JH, Lin TY, Hsieh KT, Yang JC (2010a) DNA barcoding Cinnamomum osmophloeum Kaneh. based on the partial non-coding ITS2 region of ribosomal genes. J Food Drug Anal. 18(2):128-135.

Lee SC, Lee CH, Yilin M, Ho KY (2010b) Genetic identification of Cinnamomum species based on partial internal transcribed spacer 2 of ribosomal DNA. J Food and Drug Anal. 18(4):225-231.

Lê S, Josse J, Husson F (2008) FactoMineR: an R package for multivariate analysis. J Stat Softw. 25(1):1-18.

Leguizamón J, Badenes ML (2003) Multivariate analysis as a tool for germplasm studies, example of analysis of germplasm loquat data. Acta Hortic. 606:29-35.

Mabberley DJ (2008) Mabberley's plant-book: a portable dictionary of plants, their classifications and uses. 3rd edn. Cambridge University Press.

Martinez-Calvo J, Gisbert AD, Alamar MC, Hernandorena R, Romero C, Llacer G, Badenes ML (2008) Study of a germplasm collection of loquat (Eriobotrya japonica Lindl.) by multivariate analysis. Genet Resour Crop Ev. 55:695703.

Munsell Color (1977) Munsell Color Charts for Plant Tissues. Munsell Color, Gretag Macbeth, 617 Little Britain Road, New Windsor, NY 12553-6148.

Nikolic D, Rakonjac V, Milatovic D, Fotiric M (2010) Multivariate analysis of vineyard peach (Prunus persica $\mathrm{L}$. Batsch.) germplasm collection. Euphytica. 171:227-234.

Perez S, Montes S, Mejia C (1993) Analysis of peach germplasm in Mexico. J Am Soc Hortic Sci. 118:519-524.

Qui LJ, Xing LL, Guo Y, Wang J, Chang RZ (2013) A platform for soybean molecular breeding: the utilization of core collections for food security. Plant Mol Biol. 83:41-50.

Rao VR, Hodgkin T (2002) Genetic diversity and conservation and utilization of plant genetic resources. Plant Cell Tissue Organ Cult. 68(1):1-19. 
Rathnathunga EUU, Senanayake G, Dissanayake N, Seneweera S, Geekiyanage S (2016) Development of a mini core collection from Sri Lankan traditional rice for flowering time variation. Aust J Crop Sci. 10(9):1357.

Rathnathunga EUU, Geekiyanage S (2017) Responses of Sri Lankan traditional rice to photoperiod at early vegetative stage. Pak J Bot. 49(1): 63-66.

Ravindran S, Balakrishnan R, Manilal KS, Ravindran PM (1991) A cluster analysis study of Cinnamomum from Kerala, India. Feddes Report. 102:13-21.

Rema J, Krishnamoorthy B, Mathew PA (1997) Vegetative propagation of major tree spices - a review. J Spices Aromat Crops. 6(2):87-105.

Ren J, Yu Y, Gao F, Zeng L, Lu X, Wu X, Yan W, Ren G (2012) Analysis of Genetic Structure in the USDA Rice Mini-Core Collection Using the SQUAMOSA Promoter-binding-like Gene Family. Rice Genomics Genet. 3(1):1-7.

Ruiz D, Egea J (2008) Phenotypic diversity and relationships of fruit quality traits in apricot (Prunus armeniaca L.) germplasm. Euphytica. 163:143-158.

Sandigawad AM, Patil CG (2011) Genetic diversity in Cinnamomum zeylanicum Blume. (Lauraceae) using random amplified polymorphic DNA (RAPD) markers. Afr J Biotechnol. 10:3682-3688.

Santra M, Matthews SB, Thompson HJ (2013) Development of a core collection of Triticum and Aegilopsspecies for improvement of wheat for activity against chronic diseases. Agri Food Sec. 2(1):4.

Sohrabi M, Rafii MY, Hanafi MM, Siti Nor Akmar A, Latif MA (2012) Genetic diversity of upland rice germplasm in Malaysia based on quantitative traits. Sci World J. 2012.

Soulange JG, Sanmukhiya VMR, Seeburrun SD (2007) Tissue culture and RAPD analysis of Cinnamomum camphora and Cinnamomum verum. Biotechnol. 6:239-244.
Sri Lanka Customs (2017) Sri Lanka Customs Annual Performance Report 2017. Sri Lanka Customs.

Studnicki M, Mądry W, Schmidt J (2013) Comparing the efficiency of sampling strategies to establish a representative in the phenotypic-based genetic diversity core collection of orchardgrass (Dactylis glomerata L.). Czech J Genet Plant Breed. 1:36-47.

Thomas J, Kuruvilla KM (2012) Cinnamon. In: Peter KV (ed) Handbook of Herbs and Spices, 2nd edn. Vol. I. pp. 182196.

Warrier PK, Nambiar VPK, Ramankutty C (1994) Indian medicinal plants a compendium of 500 species, Vol. II. Orient Longman Ltd., Madras, India.

Wijesinghe KGG, Gunarathna WDL (2001) Characterization of true Cinnamon (Cinnamomum verum Persl) based on leaf morphology and their relationship with yield and quality. Sri Lanka Association for the Advancement of Science. $57^{\text {th }}$ Annual Session Proc Part I, pp. 42.

Wijesinghe KGG, Pathirana R (2000) Germplasm screening and varietal development of cinnamon (Cinnamomum verum Presl.). In: Senarathne $R$, Dayathilake DA (ed) Revitalization of Cinnamon Industry in Sri Lanka, Premadasa Printers, Matara, Sri Lanka. pp. 15-17.

Yilmaz KU, Kargi SP, Kafkas S (2012) Morphological diversity of the Turkish apricot (Prunus armeniaca L.) germplasm in the Irano-Caucasian ecogeographical group. Turk J Agric For. 36:688-694.

Zhang Y, Zhang X, Che Z, Wang L, Wei W, Li D (2012) Genetic diversity assessment of sesame core collection in China by phenotype and molecular markers and extraction of a mini-core collection. BMC Genet. 13(1):102. 